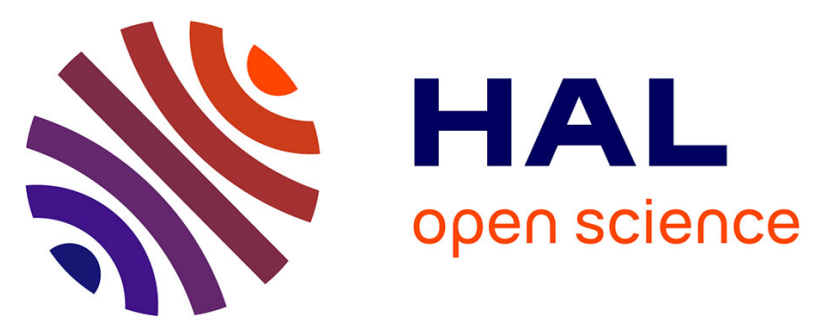

\title{
Assessing Social Sustainability of Products: An Improved S-LCA Method
}

\author{
Michele Germani, Fabio Gregori, Andrea Luzi, Marco Mengarelli
}

\section{To cite this version:}

Michele Germani, Fabio Gregori, Andrea Luzi, Marco Mengarelli. Assessing Social Sustainability of Products: An Improved S-LCA Method. 12th IFIP International Conference on Product Lifecycle Management (PLM), Oct 2015, Doha, Qatar. pp.529-540, 10.1007/978-3-319-33111-9_48 . hal01377479

\section{HAL Id: hal-01377479 \\ https://inria.hal.science/hal-01377479}

Submitted on 7 Oct 2016

HAL is a multi-disciplinary open access archive for the deposit and dissemination of scientific research documents, whether they are published or not. The documents may come from teaching and research institutions in France or abroad, or from public or private research centers.
L'archive ouverte pluridisciplinaire HAL, est destinée au dépôt et à la diffusion de documents scientifiques de niveau recherche, publiés ou non, émanant des établissements d'enseignement et de recherche français ou étrangers, des laboratoires publics ou privés. 


\title{
Assessing social sustainability of products: an improved S-LCA method
}

\author{
Michele Germani ${ }^{1}$, Fabio Gregori ${ }^{1}$, Andrea Luzi ${ }^{1}$, Marco Mengarelli ${ }^{1}$
}

${ }^{1}$ Department of Industrial Engineering and Mathematical Sciences, Università Politecnica delle Marche, Ancona, Italy

m.germani@univpm.it, [f.gregori; a.luzi; m.mengarelli]@pm.univpm.it

\begin{abstract}
To preserve proper growth of the planet, industries have to increase sustainability of produced good according to the compliance and governance regulations for NPD (new product development). Sustainability concerns economical, environmental and social aspects; among these issues, the last theme is the less argued in literature and this paper focuses on the social life cycle assessment of products. One of the crucial aspects of S-LCA, is the definition of impact categories and involved stakeholders. This work, proposes a new S-LCA methodology, according to UNEP/SETAC framework. After the clarification of stakeholders, categories and general notions already known on S-LCA, a test case is shown where the new approach is implemented. In this use case, stakeholders from an Italian product line are analysed, then categories of attribution of social impacts are outlined. The paper offers a step-by-step procedure useful to verify the S-LCA theories currently available on a practical industrial case, defining also weaknesses that might be addressed in future studies.
\end{abstract}

Keywords: social life cycle assessment, S-LCA, sustainability

\section{Introduction}

Nowadays one of the main challenges for product developers and designers is to meet sustainability standards. Beyond quality standards, products must fit with rigid rules to guarantee society's growth. This overall improvement passes through the sustainable development that found its basis on the following three pillars: People, Planet and Profit/Prosperity. A "sustainable" product should have low environmental impacts, with low costs and light human effects, in its entire lifecycle. Social life cycle impacts, that represent the social effect on people of a product or a service along its life cycle, are the less argued in literature with only a few articles that points out lacks and opportunities of this methodology.

To improve the knowledge about social issues estimations, in this paper, a revised social life cycle assessment (S-LCA) method is proposed, compliant with the UNEP/SETAC guidelines; its efficiency is tested on a real case study. The method developed offers a new way to acquire data for the inventory, redefining also some area of interests from UNEP's framework. After a clear definition of the goal of the analysis, the stakeholders involved into the lifecycle of the product are identified. The 
primary data are acquired through surveys, and the results are then put together, defining social impact indexes. Indexes are a crucial part for the S-LCA, in fact, a clear identification of standard indexes has not yet been discovered in literature; this methodology has been applied in a kitchen sink value chain to underline the importance of indexes that fits various social aspects that should be globally accepted. This paper is a part of an extended study about the proposed S-LCA methodology. In this work, the whole method is proposed, the inventory phase of the analysis and the relative use case application is explained.

\section{SETAC/UNEP Methodology Overview}

It is well known that the sustainable development should meet needs of the present situation without compromising the ability of future generations to meet their own [1]. In this context it is important to take into account social issues that can be evaluated through a social life cycle assessment. As mentioned on UNEP/SETAC guidelines [2], a social and socio-economic Life Cycle Assessment (S-LCA) is a social impact (and potential impact) assessment technique that aims to assess the social and socioeconomic aspects of products and their potential impacts along their life cycle, from the extraction of raw materials, up to the product final disposal.

The work of Andrews et al. [2] provides the main recognized guidelines to conduct a socio-economic assessment; it provides a map, for stakeholders engaging in the assessment of social and socio-economic impacts of products life cycle. Moreover, the Methodological sheets for sub-categories in S-LCA [3] provides a tool to conduct S-LCA studies giving detailed information for each subcategories introduced in the Guidelines, organized by stakeholder category. The methodology here proposed is rooted on the UNEP framework [2] and it is also inspired by the S-LCA methodological sheet [3].

There are a few studies based on the S-LCA guidelines, and in some cases inadequacies in terms of inventory and interpretation of data are pointed-out. Franze and Ciroth [4] provided a S-LCA study to compare the impacts related to the roses cutting between Ecuador and Netherlands. Results have been presented in a simple and intuitive manner, but a scale that measures the impacts has not been clearly identified. Differences in cultural heritage and conditions between the two countries affects the study, and the measurable gap between these two scenarios is not clearly defined. In 2013 Foolman and Ramjeeawon [5] proposed a new method to aggregate and analyse the social inventory data; the categories and the sub-categories according to the UNEP-SETAC guidelines to perform a study on used PET bottles have been identified.

In literature there are few works that do not take into account the previous guidelines. One example is the work of Labuschagne and Brent [6], which shows a framework where social sustainability criteria are introduced for the South African process industry, and a social impact indicator calculation has been presented. Calculations are based principally on statistics, therefore social footprint information is not available for all the considered categories. Umair et al. [7], provided a study to investigate the social impacts of informal e-waste recycling in Pakistan. The goal of 
the study is to provide input for improved decision making tools by collecting primary data on processes and practices using the UNEP framework for S-LCA, but the work is strictly limited to the application of the UNEP guidelines. Instead, Macombe et al. [8], presented a work with the aim to analyse possibilities and development needed in a complementary approach. This approach represents the evaluation of social impacts in LCA by reviewing the general context, taking a closer look at the empirical case of three different raw materials: palm oil, forest biomass, and algae, within biodiesel production. This study has been conducted considering three different levels: company, region, state. At the same time, Martínez-Blanco et al. [9], proposed a study in which S-LCA has been conducted to integrate social aspects into the environmental and economic assessments of fertilizers, comparing three different alternatives: compost, nitric acid and potassium nitrate.

Social aspects must consider as a fundamental task the stakeholders involvement In this view, Souza et al. [10], proposed a study in which a methodology is developed and applied for stakeholder consultation regarding the selection of LCSA (Life Cycle Sustainability Assessment) impact categories, focusing on social and economic issues.

UNEP guideline highlights areas where further research is needed; the proposed work is also settled in this context. The stakeholders and related categories proposed by the guidelines are not easily evaluable in many assessment contexts. One example is the impossibility to consider the category "indigenous rights", for a EU context, because there is not indigenous presence in the European continent. The main issues identified on those documents concerns data inventory and their interpretation, which consist in the main challenge of the present work.

Here an improved method for a better data collection is provided, in order to collect in a more efficient way S-LCA inventory data. This method has been applied in a socio-economic assessment of kitchen sink production; this is also the first study that considers Italian companies and laws, for a S-LCA analysis.

Within the ISO 26000:2010 [11], stakeholders are defined as organizations or individuals that have one or more interests in each decision or activity of an organization. Moreover, stakeholders can be divided in clusters of people that have similar interests within the product systems boundaries. In a life cycle approach those categories are related to every product phase "from cradle to grave". UNEP identifies 5 different stakeholder categories:

1. Workers

2. Local community

3. Society

4. Consumers

5. Value chain actors

Those categories are deemed to be the main group categories potentially influenced by the life cycle of a product in terms of socio-economic impacts. In the present work these categories are considered, but they are analysed with more accuracy thanks to the new proposed method. 


\section{Methodology}

Through this work, an improved method to perform social life cycle assessment analysis is proposed. This method fills the gap of the previous literature works that follow step by step the UNEP/SETAC procedure.

The strength of this new method is related to the development of an improved analysis in the inventory phase to obtain more effective results. In fact, a custom data identification procedure is driven by the specific analysis goal, and the procedure opens to a more thoughtful analysis. In other words, decisions that influence the analysis itself can be undertaken, pointing out certain social related topics. Moreover this procedure encourages the acquisition of specific data for each real use case. The S-LCA method proposed in this paper is outlined in Fig. 1. The figure shows the conceptual flow of the new S-LCA procedure developed.

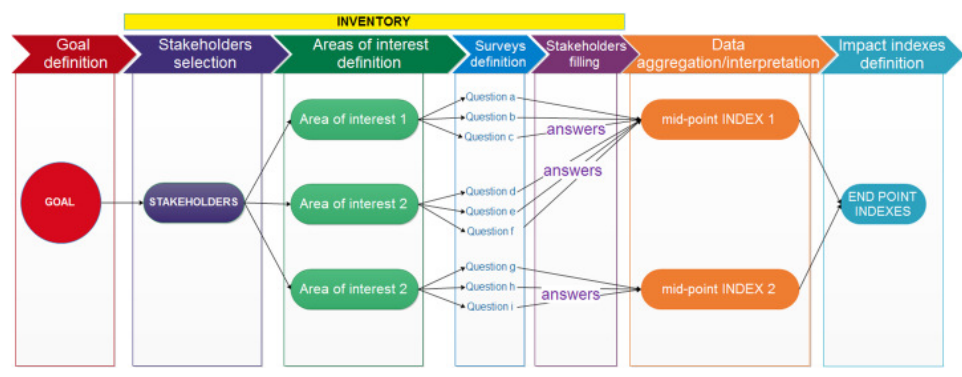

Fig. 1. New S-LCA method structure

The aforementioned method is based on 4 main phases:

1. Goal definition

2. Inventory
a. Stakeholders selection
b. Areas of interest definition
c. Surveys definition
d. Stakeholders filling

3. Data aggregation/interpretation

4. Impact indexes definition

1. Goal definition. This is the starting phase of the method, where many analysis features are defined. In this first stage the subject of the social analysis, also called the goal, is decided. The goal is what the analysis wants to assess. Through the proposed method it is possible to assess social consequences of different scenarios; analyses can be focused on different levels, such as product development, specific processes, and overall company assessment. Depending on the analysis, the goal will be different and it will include different considerations. It is important to clearly define the goal in order to make effective decisions into the inventory analysis. In this phase the system boundaries are also defined. 
2. Inventory. Once the goal of the social analysis has been well defined, it is necessary to fulfil the data acquisition process. In this phase surveys are prepared. Surveys are modelled in relation to the identified areas of interest (AoI) and in relation to the selected stakeholders. The chosen areas of interest are the main drivers of the surveys definition phase. Different actors, depending on the stakeholder category, will then fill the surveys. This phase is one of the strengths of the proposed method, compared the methods already known in literature. As previously mentioned, in fact, some social data are often lost without the usage of a structured acquisition phase. The inventory proposed within this new method, covers the lacks of previous works, narrowing effectively the social issues related to the analysis. The definition of specific social Area of interests supports the data collection.

2.a Stakeholders selection. This is the first step for the inventory phase. Here, depending on the goal of the analysis, the stakeholders are defined. According to the S-LCA guidelines, stakeholders are intended as any group of person that plays a certain role contextually to the goal of the analysis. Stakeholders Categories here defined are the same proposed by UNEP/SETAC [2]. In this method, two main categories of stakeholders are considered: active and passive actors. Active actors are those clusters of people that act directly on the product/process analysed through the social assessment. Those people, through their action can influence social effects Passive stakeholders are those that are socially affected by the value chain without directly interact with it (e.g. the local community members). Depending on the system boundaries previously defined, it is possible to make the stakeholder selection cut-off.

2.b Area of interest definition. An area of interest is here defined as a topic that is related to socio-economic consequence of a project, measurable through the analysis. In relation to the goal some different area of interests are defined. For each stakeholder multiple area of interest could exists, therefore it is important to define correctly those areas to enquire the right questions to stakeholders. In the case study section different areas of interest are shown, some of these are generic, while other are customised for the present case study. AoI are identified in order to clearly define which clusters of data are needed for the social assessment. AoI are topics that will be examined in deep through surveys: each area of interest embeds many features that will be identified through specific questions.

2.c Surveys definition. The main tools used to acquire data for the analysis are the surveys. They are prepared according to the areas of interest and stakeholders previously selected. Each area of interest is depicted through 2-3 questions; each question highlights a feature related to that AoI. The AoI will be hidden into surveys: only data evaluators will know which AoI questions are referred to. Surveys are different for each group of stakeholders; customized questions are proposed through an online procedure to all identified stakeholders. Surveys follow strict rules: each survey is structured in a maximum of 20 questions with the aim to fill out the survey in a simple and quick manner. There are two types of questions: qualitative and quantitative. Qualitative questions are open-ended ore multiple-choice questions, quantitative ones are characterized by a scale based choice (mainly 0-5 points) or an exact number to insert (e.g. number of employers). Each survey contains more multiple-choice questions than the open-ended ones to facilitate the data interpretation phase. 
2.d Stakeholders filling. Once stakeholders receive surveys, they are entitled to fill up the survey. Answers will be anonymous, to guarantee privacy, obtaining objective responses not influenced by external pressures.

3. Data aggregation/interpretation. This phase aims to aggregate and interpret surveys results. A neutral S-LCA evaluator acts in this phase. It is important that the identified figure for this task does not belong in any way to the considered value chain, otherwise conflicts of interest occur. The main output coming from this phase is the creation of mid-point social indexes. The hard work of this phase is related to the aggregation of quantitative and qualitative answers. Mathematical algorithms will be implemented to aggregate surveys results; from the clustering of the results will emerge groups of answers having similar impacts for different stakeholders. The interpretation of those clustered answers aims to define mid-point indexes. Different answers for different stakeholders could then flow in the same mid-point index. In fact, each mid-point index is a measurable value that contains similar impacts coming from different area of interests.

4. Impact indexes definition. The final results of the analysis are presented and discussed. End-point indexes are made of different mid-points that are aggregated, to obtain a final value to measure the socio-economic impacts. As reported in the ISO 14040:2006 [12], an impact category is defined as a "class representing environmental issues of concern to which life cycle inventory analysis results may be assigned". This definition can be extended also to the social issue reported in the presented work.

\section{Case study}

Green Sinks, "Realization of green composite sinks substituting organic and mineral primary materials by recovered waste" is a project funded by the Life+ Programme of the European Commission. The product analysed, is made of acrylic composite materials, composed by methyl methacrylate (MMA), poly-methyl methacrylate (PMMA), and a mineral filler (quartz or cristobalite). The aim of the project is to experiment and demonstrate feasibility of $100 \%$ substitution of primary resources by treated waste and recycling of $80 \%$ of scraps and refuses produced by the process. This will allow to future market introduction of the first Green Sinks in the world. Recovered MMA, PMMA and mineral filler will permit the preservation of landscapes and primary resources use, recycling a large variety of pre- and postconsumer waste (PMMA, glass, quartz from stone industries). Life Cycle Assessment (LCA) methodology has been used both to evaluate the environmental benefits achievable, and to complete the evaluation of the overall sustainability. For this purpose an S-LCA analysis has been prepared, and this methodological framework has been reported in the paper.

Now, the previously presented method is applied; and in particular in this paper is shown the procedure till the step of the areas of interest definition. 


\subsection{Goal definition}

The goal of this S-LCA analysis, according to the project, is to identify and compare the socio-economic effects between the production of a green kitchen sink, and the production of a kitchen sink made by virgin raw materials. The considered system boundaries refer to the whole value chain of the production of the kitchen sink, "from cradle to grave".

\subsection{Stakeholders selection}

Here starts the inventory of this analysis. In this phase the actors that in a passive or active manner are related to the goal of the analysis are identified. The active stakeholders involved are suppliers, sink producer, costumers; the local community and society are the passive ones. In the following section the chosen stakeholders are detailed; Area of interests are shown only for Workers, Customers and Local community.

Stakeholders (Workers). For this topic two types of questionnaires are presented with the aim to evaluate the social impact related to the manufacturing of the kitchen sink. Workers are here classified into two categories: people who work in the production area and people who work in the technical/management area. The questionnaires have the purpose to define the working condition, highlighting the workers satisfaction, health, safety, and other related social topics.

For this stakeholder category the following areas of interest are identified.

Professional training: considering the continuous request of qualified work, the people training within the industry plays an important role in the growth of employees skills. In this view it is important to evaluate how many training hours are spent to also improve the employers' knowledge of standards and best practices about sustainable manufacturing.

Professional growth: the personal satisfaction is also related to this area, during the working period in the industry. The professional training done and the possibility to improve personal skills, making different activities can improve this topic.

Economic satisfaction: the salary is one of the most important aspects related to the worker satisfaction: the wage permits the worker to realise itself outside the industry, supporting himself and (eventually) his family. The trade-off among salary, the type of work and the number of work hours is a fundamental issue.

Social inequality: different treatment of the workers can bring to social inequality. Discriminations regarding sex, nationality, religion, are important themes debated over the last decades. In this area also the possibility for the worker to freely aggregate and set up associations, etc., can be included. In many cases the social inequality is related to different trade union representatives.

Risks at work: The aim of this area is to evaluate the risk level along the manufacturing activities. Risk is related to the environment in which the people work and the worker's behaviour. The number of accidents and injuries quantifies the risk level. 
Diseases related to work: A crucial aspect is the birth of occupational illnesses. In fact, risks can be related also to operations that bring to diseases such as carpal tunnel syndrome, respiratory diseases, sight reduction etc.

Employment scenario: Social sustainability is also related to the stability of the workplace. The growth or the decrease of the workers employed can be measured by absolute values (trend of employment during 5 years for example) and relative values that represent rate of layoffs and hiring; the number of employees could remain the same but there is a continuous change of the people.

Work opportunities for the local community: To guarantee a proper social growth the local community must be involved. In this case the number of employees who live in the local area represents the local involvement.

Stakeholders (Value chain actors). All the actors not explicitly mentioned in other stakeholder categories, belongs to this one. In the case of a wide supply chain is important not to extend the complexity of questions related to this category because some data could be lose or wrongly estimated while acquiring information. Here, for this case study, are mainly involved suppliers of the sink producer.

Stakeholders (Society). For this topic, no questionnaire would be submitted However, an internal analysis would be carried out in order to assess the impact of the kitchen sink to the society. The society it is a very large group, therefore, it is necessary to clearly states the boundaries considered. In this study the society is intended as all the humans beings that are directly or indirectly involved along the kitchen sink life cycle

Stakeholders (Customers). Once the sink has been realised, it is sold to a kitchens' manufacturer. This company is identified as the first customer of the sink manufacturer and in this study it represents the customer.

Three different areas of the company structure have been identified according to the functional organization model structure of a company: Purchasing, Manufacturing and Sales departments. These three company sectors have been chosen as they all interact with the kitchen sink from different point of views. Three different questionnaires have been here realized. For each subcategory one or more questions are proposed. The final customer, the one who buys the kitchen, is not included in this area of interest.

Health: The product traded should not influence in any case the state of health of the workers that are directly or indirectly related to it. Kitchen sinks are included within the ISO 19712-1:2008 [13], which establishes a classification system for solid surfacing materials according to their performance. The model under analysis is supposed to be compliant to the present regulation. There should be a sign "label" that confirms the approved status of the product.

Safety: The product should not be harmful for any operator that directly or indirectly operates with it. In this context, the list of possible interactions with the sink should not exclude the final customer (the one who buy the kitchen), even though he is out of the system boundaries. Potential danger should not be allowed. When this is not possible due to the nature of the product itself, it should be clearly stated which parts, or actions could procure safety issue. 
Feedback: The customer should be able to express a feedback on every purchase. The customer should not be scared to externalize his opinion. The seller should also give instruments and possibilities to do so. For example, the seller could ask for feedback on a traded product by using questionnaires and it should make the buyer comfortable in expressing his opinion.

Privacy: In order to foster a successful partnership and to ease the interaction between seller and customer, a certain amount of information must be shared. Nevertheless, privacy should always be respected. Meaning that the customer should always feel "safe" in sharing information with his seller. As an example, the kitchen sink manufacturer should provide a form that describes how sensible data from customer are treated

Transparency: The customer is able to evaluate the performance of the product in a strict correlation to the social responsibility perspective. The seller/producer is able to show in a transparent way his attitude respect to sustainability issues. The customer on his side, is aware of the position undertaken by the producer/seller and thanks to that is able to think about political choices undertaken by the producer. For instance, the seller could show to his customers which sustainability actions or strategies have been undertaken in order to realise the kitchen sink.

Responsibility shares concerning after-use treatments: The producer sends production scraps for further treatment in developing countries. These wastes might be seen as potential danger for poor people that look for high value things into landfill plants. The producer should follow regulations concerning end of life management. As an example, the kitchen sink manufacturer could provide documents concerning the disposal of the product.

Imagine perceived from the final customer: The product contributes to define a positive image or a solid attitude towards sustainability issues. By acquiring/using the product, the customer itself is perceived from the outside, as someone which is aware of the importance of environmental issues.

Knowledge and awareness: The customer gains knowledge and expertise in the field of sustainable products. Its involvement in the "green" economy is enhanced by the trade of the kitchen sink or in general by the collaboration with the producer/seller. For instance, knowledge and expertise gained by the kitchen sink manufacturer could be shared as an aspiring action toward the involvement of "green" reaction within the kitchen assembler.

Post purchase engagement: The relation between the two parties is kept "alive" also when the transaction is over. The liaison is not merely constricted in the pure economic ambient but it goes beyond. The relationship level is deep and therefore involves both parties in a solid way, fostering future collaborations and initiatives. As an example, from the trade of the "green" kitchen sink, a collaboration in financed projects for sustainability could be proposed from both sides.

The table 1 represents an extract of the survey for this stakeholder category, according to AoI mentioned. In the table, the first column is presented to favour a proper link between AoI and questions, but it will be hidden when the survey will be proposed to end-users. 


\begin{tabular}{|c|c|c|c|c|c|c|}
\hline Area of interest & Question & & & & & \\
\hline Health & $\begin{array}{l}\text { Does the product compromise the health } \\
\text { status of direct and indirect operators? }\end{array}$ & 1 & 2 & 3 & 4 & 5 \\
\hline Safety & $\begin{array}{l}\text { Is it the product dangerous for all the } \\
\text { operators that deal with it? }\end{array}$ & & Yes & & No & \\
\hline \multirow{2}{*}{ Feedback } & $\begin{array}{l}\text { Is the customer able to express his/her } \\
\text { feedback? }\end{array}$ & & Yes & & \multirow[t]{2}{*}{ No } & \\
\hline & $\begin{array}{l}\text { The customer is free to express his own } \\
\text { opinion without being afraid of the }\end{array}$ & & Open & iswer & & \\
\hline \multirow{2}{*}{ Privacy } & $\begin{array}{l}\text { The customer has no worries concerning } \\
\text { the information shared with the }\end{array}$ & & Yes & & \multirow[t]{2}{*}{ No } & \\
\hline & $\begin{array}{l}\text { The producer/seller safely keeps } \\
\text { information shared by the customer. }\end{array}$ & & Open & iswer & & \\
\hline \multirow{4}{*}{ Transparency } & $\begin{array}{l}\text { The product comes with indexes that } \\
\text { shows the contribution to social }\end{array}$ & & Yes & & No & \\
\hline & $\begin{array}{l}\text { The customer is informed concerning the } \\
\text { attitude of the producer/seller toward }\end{array}$ & & Yes & & \multirow[t]{2}{*}{ No } & \\
\hline & $\begin{array}{l}\text { If yes, how much effort has the producer } \\
\text { put in order to share this information? }\end{array}$ & & Open & iswer & & \\
\hline & $\begin{array}{l}\text { The customer has been informed on the } \\
\text { actual benefit of realizing a "green" }\end{array}$ & & Yes & & No & \\
\hline
\end{tabular}

Table 1. An extract of the survey proposed for the Stakeholder customers

Stakeholders (Local community). By previous remarks, for this case study, in this category are involved all of the people living nearby the area of the sink production plant (Plados, MC - Italy). Actors with different roles are identified within the community: People (anyone who lives within $8 \mathrm{~km}$ to the production plant), School institutions, Municipal Council. This differentiation is driven by the need to understand effectively social effects on the community from different points of view. Different surveys are developed to better understand the following area of interests.

Cultural growth: the contribution a company gives to the local heritage is defined by the efforts made to involve students and people for a value sharing. It is important for a company to establish collaboration with institution and schools in terms of students' internship or economical contribution to local cultural activity; this topic passes also by the amount of local assumptions the company board performs.

Smart Thinking: this area concerns the sharing culture the company embeds. The company often wastes a large amount of available energy or resources without sharing them with the local community. Resources include spaces, multipurpose rooms, gardens and tools; sharing these resources facilitates to build a smart community. 
Social Sensitivity: here the focus is on the attention the company owns about weak categories, local associations and event of aggregation. Only an external point of view could attest the level the company has on this topic.

Communication: the ability of the company to interact with the community is here highlighted. The local community knowledge about the company means a leading role within the territory. Positivity or negativity emerged by the community, will affect the credibility and the image of the company itself.

Attractiveness: the interesting of people in being involved in the mission of the company means an industrial relevance on the territory.

Direct pollution: it is important to take into account this area of interest; healthiness of local territory has to be guaranteed by the company. A survey proposed to people living nearby the factory will demonstrate weather or not the company behaviour affects the integrity of the environment.

\section{Conclusions and Future Work}

This paper proposed a method to perform a social life cycle assessment with a "stakeholder approach". The new method is here applied for a case study on an Italian product: only a part of the method has been applied so far, but the whole method is depicted in this paper. The new method is based on the S-LCA worldwide guidelines; a more structured approach is here developed, taking into account mainly the inventory phase, overcoming weaknesses of guidelines into the inventory phase. The method here proposed is based on 4 different phases: following those steps an effective social assessment could be accomplished. This paper focuses on the second phase of the method, the inventory. The approach, for the inventory phase, suggests the definition of many reasonable areas of interests that could lead effectively the data acquisition phase. The study of the AoI has been performed according to the present analysis. The specifications of the involved territories are also taken into account to develop areas of interest that perfectly describe the social issues related to the analysis goal. AoI are settled to pursue the goal of the analysis into relative defined system boundaries. Within those areas, different questions for each stakeholder are developed in order to acquire some detailed information for a better understanding of social impacts. Many AoI designed in this work could be implemented in different case studies for future assessments. The generic AoI presented, thanks to similarities with the present case study (territories, industrial area, etc.), will be replicable for every SLCA assessment, following the presented method. The described areas of interest could be also extended, identifying further significant AoI for future depth assessments. The use of the proposed method, according to the analysis goal, lead to a deeper understanding of the social sustainability. Through this method, social criticalities are clearly identified thanks to a detailed list of the areas of interest. In fact, the definition of the AoI lead to a better data acquisition during the inventory phase. The final results of the presented case study will be shown in future papers, when the surveys definition and their interpretation will be reported. Interpretation algorithm will be implemented to obtain measurable results. Through the analysis results, decision makers will be able to take effective choices in order to increase the 
social sustainability indexes within the boundaries of the analysis. Finally, this work is a part of a long-term research aiming at increasing the knowledge on the S-LCA topic, with the purpose to develop an efficient and unified social life cycle assessment method. This proposed method could represent a starting point for a software architecture aimed to perform socio-economic analysis.

Acknowledgments. The work has been possible thanks to the collaboration with Delta srl, within the EU project co-financed by LIFE+ Programme.

\section{References}

[1] United Nations World Commission on Environment and Development (WCED): Our Common Future (1987)

[2] Andrews, ES, Barthel LP, Beck T, Benoît C, Ciroth A, Cucuzzella C, et al.: Guidelines for social life cycle assessment of products. UNEP/SETAC Life Cycle Initiative; (2009)

[3] United Nations Environment Programme and SETAC, the methodological sheets for subcategories in social life cycle assessment (S-LCA) (2013)

[4] Franze, J., Ciroth, A.: A comparison of cut roses from Ecuador and the Netherlands. Int J Life Cycle Assess 16, 366--379 (2011)

[5] Foolmaun, R. K., Ramjeeawon, T.: Comparative life cycle assessment and social life cycle assessment of used polyethylene terephthalate (PET) bottles in Mauritius Int J Life Cycle Assess 18:155-171 (2013)

[6] Labuschagne, C. and Brent, A.C.: Social Indicators for Sustainable Project and Technology Life Cycle Management in the Process Industry, The International Journal of Life Cycle Assessment, vol. 11, no. 1, pp. 3-15 (2006)

[7] Umair, S., Björklund, A., \& Petersen, E. E.: Social impact assessment of informa recycling of electronic ICT waste in Pakistan using UNEP SETAC guidelines. Resources, Conservation and Recycling, 95, 46-57 (2015)

[8] Macombe, C., Leskinen, P. Feschet, P. \& Antikainen, R. Social life cycle assessment of biodiesel production at three levels: A literature review and development needs. Journal of Cleaner Production, 52, 205-216 (2013)

[9] Martínez-Blanco, J., Lehmann, A., Muñoz, P., Antón, A., Traverso, M., Rieradevall, J., \& Finkbeiner, M.: Application challenges for the social Life Cycle Assessment of fertilizer within life cycle sustainability assessment. Journal of Cleaner Production, 69, 34-48. (2014)

[10] Souza, R. G., Rosenhead, J., Salhofer, S. P., Valle, R. a. B., \& Lins, M. P. E.: Definition of sustainability impact categories based on stakeholder perspectives. Journal of Cleaner Production. (2014)

[11] ISO 26000:2010, Guidance on social responsibility, International Organization fo Standardization, Geneva.

[12] ISO 14040:2006 Environmental Management: Life Cycle Assessment, Principle and Guidelines, International Organization for Standardization, Geneva.

[13] ISO 19712-1:2008 Plastics Decorative solid surfacing materials - Part 1: Classification and specifications, International Organization for Standardization, Geneva. 